\title{
Wo wir zu Hause sind
}

\section{Erhard Taverna}

Dr. med., Mitglied der Redaktion

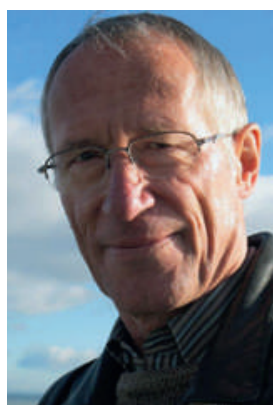

Ein alter Ladenhüter, neu verpackt, hat Roger Ulrich bekannt gemacht. Seine Studien zur Erholungszeit von Spitalpatienten wurden als Pioniertat gefeiert. Der heute in Schweden lehrende Architekturprofessor hat das Bauen im Gesundheitssektor massgeblich beeinflusst. Natur durchs Klinikfenster betrachtet mindert Stress, beruhigt Herz und Gehirn und führt zu besseren Resultaten bei psychologischen Tests.

Was da so genau abläuft und wozu diese Aussicht gut sein soll, beschäftigt seither Mathematiker, Techniker, Neurologen, Psychologen, Künstler und Städtebauer. Unberührte Natur wird es nicht sein. Braucht es dazu einen geschickten Gärtner oder reicht schon ein grüner Kunstrasen? Wo früher Landschaftsmaler unsere Sinne verführten, wirkt heute die IT-Branche. Zahlreiche Experimente und Studien belegen, dass Strukturen des Parahippocampus im Temporallappen durch visuelle Landschaftseindrücke Opiatrezeptoren aktivieren. Die maximale Reduktion auf einfache Konstanten und Grundmuster bringt fraktale Bildrelationen oder Abfolgen von Hell-dunkelMustern, im fMRI als Raumfrequenz beschrieben, ins Spiel.

\section{Wo früher Landschaftsmaler unsere Sinne verführten, wirkt heute die IT-Branche.}

Lassen sich Erregungsmuster kontrolliert simulieren, erzeugt auch ein gepixelter Wald die gewünschte Wirkung? Die US-Firma Sky Factory produziert auf der Grundlage erfolgreicher Versuche Filme, die in Spitälern, auf Onkologieabteilungen und in Ärztezimmern die Stimmung positiv beeinflussen sollen. Die Gefühlsforschung animiert Architekten zur Gestaltung neuer Arbeitsräume. Wo immer mehr Menschen untertags bei Kunstlicht arbeiten, können Webcam-Projektionen die fehlenden Fenster ersetzen. Der Architekt und Psychologe Colin Ellard vergleicht in seinem Buch Places of the Heart: The Psychogeography of Everyday Life [1] die vielen PC-Schirme mit künstlichen Ersatzfenstern in eine Umwelt, die früher ausschliesslich Mauern in ein Innen und Aussen unterteilten. Sein faszinierender Rundblick beschreibt die neue Szene der Designer-Koryphäen wie Philip Beesley, die an allen grossen Biennalen das Publikum mit Kunstinstallationen verblüffen, die über interaktive Netzwerke aus Mikroprozessoren Emotionen manipulieren. Diese Hylo- zoic Series oder Sentient Chambers sind lernfähige Kunstwelten, die äusserlich dem hochartifiziellen 3DDschungel aus dem Film Avatar gleichen. Interaktivbewegliche Acrylbäume und einfühlsame Lichtgirlanden reagieren auf Besucher wie Seeanemonen in einer üppigen Korallenfauna.

Der von Ulrich beobachtete Natureffekt zieht immer weitere Kreise. Auf dem bald vollständig urbanisierten Planeten sind naturbelassene Oasen Luxusinseln für sehr Reiche. Die Erfinder schwärmen von einer Poesie des Raums, von lebendiger Architektur, die für das Wohlbefinden der Durchschnittsbewohner sorgt. Das neue

\section{Wo immer mehr Menschen untertags bei} Kunstlicht arbeiten, können Webcam-Projektionen die fehlenden Fenster ersetzen.

Zuhause ist mit Sensoren, Displays, virtuellen Realitäten und 3D-Fabrikationen vollgepackt. Neue Materialien und Fühltechniken verändern das Bauen. Das permanente Tracking über Smartphones von Menschen als Konsumenten in Shoppingzentren oder als Museumsbesucher bestimmt das Angebot. Städtebauer benützen die gleichen Methoden. Eine gute Strasse ist so zu konzipieren, dass sich Fussgänger im Schnitt mit fünf Stundenkilometern bewegen und alle fünf Sekunden irgendetwas Interessantes zu sehen bekommen. Da Bewohner einer Grossstadt für psychische Krankheiten wie Depressionen und Schizophrenie anfälliger als Landbewohner sind, soll gute Planung die Langeweile vertreiben und die Neugier anregen. Die Informationstheorie empfiehlt Komplexität als Mittel gegen monoton genormte Rasterfassaden und eintönige Glassfronten. Alexander Mitscherlichs Unwirtlichkeit unserer Städte [2] bleibt eine "Anstiftung zum Unfrieden». 50 Jahre später helfen Cyber-Handschuhe und Augmented-Reality-Brillen durch Mitscherlichs unveränderte «suburbane Sosse aus Stadtwüsten und EFH-Weiden».

Colin Ellard baut auf die Technik. Soziale und politische Probleme oder die zunehmende Entfremdung des Einzelnen von seiner realen Umwelt sind nicht sein Ding. Seine Strategien setzen auf Geotracking Smartphones. Sage mir welche Strassen und Plätze eine schlechte Stimmung erzeugen, und das Programm führt dich auf sicheren Wegen an dein Ziel. Gefühlsprothesen schützen mein Ego mit unsichtbaren Zäunen. Der denaturierte Rest bleibt aussen vor. 